\title{
The Role of an Effective Supervisor: Case Studies at the University of Manchester, United Kingdom
}

\begin{abstract}
$\mathrm{PhD}$ programmes in the British education system are not based on formal lectures and credits, the supervision requirements of $\mathrm{PhD}$ students in the UK are generally greater than those who study under more formal and structured programmes, as is the case in the US and Europe. Therefore, the role of the $\mathrm{PhD}$ supervisor in the British education system is critical to a successful $\mathrm{PhD}$ process. Poor supervision can have a significant impact on students, not only limiting the quality of their work, but also their motivation. There are many opinions regarding the responsibilities of supervisors. Past research had shown that only highly unusual graduate students successfully completed their research degree programs if the relationship with their supervisors is poor. There are many factors that could contribute to poor achievement of foreign students and one of the most important critical factors found which contributed to this problem is the weaknesses in supervision they receive. This research studies PhD students' experience in relation to effective supervision by focusing at what $\mathrm{PhD}$ students want from their supervisor and what they have. This study is using the case study method where three Malaysian $\mathrm{PhD}$ students from three major disciplines of study namely arts, science and social science were involved in this research. As a result, the research had developed the best effective way of one supervisor should react from the students' perspectives.
\end{abstract}

Keyword: Foreign Student, Graduate Student, $\mathrm{PhD}$, Supervisor, Supervision 